\title{
LEADERSHIP OF PRINCIPAL DEVELOPING LEARNING ORGANIZATION IN SD NEGERI BULUKANTIL SURAKARTA
}

\author{
Nenik Hidayah \\ Universitas Sebelas Maret \\ nenikhidayah44@gmail.com
}

\section{Article History}

accepted 09/07/2018

approved 01/08/2018

published 17/09/2018

Keywords

leadership, principal,

learning organization

\begin{abstract}
Technological developments require educational actors to keep learning in order to keep pace with technological developments. In order to maintain the quality and trust of the school institutions, then as an educational institution should be able to compete with schools and even with other non-formal institutions. This article is intended to describe the principal's leadership in implementing the school as a learning organization at SD Bulukantil Surakarta. The method that used in writing this article is qualitative research. The leadership of the principal at SD Negeri Bulukantil Surakarta has fulfilled five school requirements as a learning organization that includes personal skills, mental models, shared vision, team learning, and system thinking. The impacts of implementing learning organizations can be seen from the achievements of teachers, principals, learners and even school institutions. Learning organizations can be applied in other school institutions to improve their existence.
\end{abstract}

Social, Humanities, and Education Studies (SHEs): Conference Series https://jurnal.uns.ac.id/shes
p-ISSN 2620-9284

e-ISSN 2620-9292 


\section{PENDAHULUAN}

Sekolah sebagai organisasi pendidikan memiliki peranan yang sangat penting dalam mengembangkan potensi peserta didik, sebagaimana definisi pendidikan yang termuat dalam Undang-Undang Sisdiknas No. 20 tahun 2003, bahwa pendidikan merupakan usaha sadar dan terencana untuk mewujudkan suasana belajar dan proses pembelajaran agar peserta didik secara aktif dan mengembangkan potensi dirinya untuk memiliki kekuatan spiritual keagamaan, pengendalian diri, kecerdasan, akhlak mulia, serta keterampilan yang diperlukan dirinya, masyarakat, bangsa, dan negara. Dari definisi pendidikan tersebut, dapat diambil benang merah, bahwa esensinya pendidikan mengarah pada "penciptaan suasana belajar yang efektif" dan proses "pembelajaran yang interaktif". Dalam hal ini, proses pembelajaran yang dilakukan merupakan aspek utama organisasi sekolah, karena dalam proes pembelajaran terjadi proes perubahan kemampuan peserta didik sebagai evaluasi dari sistem pendidikan yang dilakukan di sekolah.

Dalam perkembangan pendidikan di Indonesia banyak terjadi perubahan mengenai perubahan ilmu pengetahuan dan teknologi, misalnya perubahan kurikulum yang akan membawa perubahan dalam proses pembelajaran dan teknologi juga dapat mempermudah pelaksanaan pembelajaran serta pengelolaan pendidikan. Menurut Ahmadi dan Amri (2014) Kurikulum 2013 mengharapkan peserta didik mampu mengembangkan nalar dibanding hafalan. Dalam kurikulum ini siswa dituntut untuk mampu mengeksplor dirinya untuk mendapatkan hal yang baru.

Untuk tetap menjaga kualitas dan kepercayaan terhadap organisasi sekolah tersebut, maka sebagai lembaga pendidikan harus mampu berkompetisi dengan sekolah-sekolah dan bahkan dengan lembaga-lembaga nonformal lainnya. Akdon (2011) mendefinisikan organisasi merupakan sistem yang sinergis atau integral, yang didalamnya terdapat subsistem dan komponen-komponen yang relationship atau saling berhubungan erat. Setiap organisasi mempunyai tujuan masing-masing, dan untuk mencapainya juga berbeda-beda.

Agar dapat berkompetisi organisasi sekolah setidaknya mampu melihat berbagai kebutuhan dan harapan stakeholder. Adanya kebutuhan dan harapan yang dinamis, sekolah harus mampu berubah untuk menyesuaikan diri dengan kondisi makro yang berkembang. Pencapaian itu dapat dilakukan dengan mengelola sumber daya manusia dengan baik. Organisasi yang memfasilitasi supaya kemampuan sumber daya manusianya untuk dapat terus belajar dan berkembang disebut "learning organization" (LO). Sebagaimana disampaikan Pedler, dkk., dalam Muhaimin, dkk. (2009) bahwa organisasi pembelajar (learning organization) adalah sebuah organisasi yang memfasilitasi pembelajaran dari seluruh anggotanya dan secara terus menerus untuk mentransformasikan diri.

Learning organization dapat meningkatkan kinerja keseluruhan dari mitra sebuah organisasi seperti yang di sampaikan Divesh Ojha, dkk (2018) "Researchers have also examined the role of organizational learning in addressing specific challenges of supply chain organizations such as improving the overall environmental performance of supply chain partners".

Menurut Hermino (2014) pembelajaran organisasi berkenaan dengan organisasi yang secara terus-menerus dan terencana memfasilitasi anggotanya agar mampu terus-menerus berkembang dan mentransformasikan diri baik secara colektif atau individual dalam usaha mencapai hasil yang lebih baik dan sesuai dengan kebutuhan yang dirasakan bersama antara organisasi dan individu didalamnya.

Untuk mendapatkan sesuatu informasi baru untuk meningkatkan kinerja anggota organisasi maka dibutuhkan suatu proses pembelajaran organisasi. Informasi tersebut dikemas dalam sebuah pengetahuan. Sebagaimana di sampaikan Hult, dkk., (2000) "stated that different stages of manufacturing not only involve a physical transformation 
of goods, but also involve information flows. Raw information, in turn, is transferred into knowledge and action through organizational learning process".

Dari beberapa pendapat diatas dapat ditarik kesimpulan bahwa pembelajaran organisasi (learning organization) adalah sekumpulan orang dengan tujuan sama yang tergabung dalam suatu sistem, secara terus menerus belajar dan mentransformasikan diri untuk dapat mencapai tujuanya.

Sekolah/ madrasah dapat menjadi sebuah organisasi pembelajar dengan beberapa prasyarat seperti yang disampaikan Sange dalam Muhaimin, dkk., (2009) sebagai berikut:

1) Keahlian Pribadi (Personal Mastery)

2) Model Mental (Mental Model)

3) Visi Bersama (Shared Vision)

4) Pembelajaran Tim (Team Learning)

5) Pemikiran Sistem (System Thinking)

Penguasaan pribadi (personal mastery) merupakan suatu budaya dan norma organisasi yang menuntut seluruh individu untuk mengenali dirinya sendiri. Dengan demikian individu tersebut akan mengetahui apa yang harus dilakukan ataupun tidak harus dilakukan. Penguasaan pribadi juga akan mendorong individu untuk mengenali potensinya dan mengembangkan dirinya kearah sasaran-sasaran dan tujuan-tujuan yang mereka pilih.

Model mental (mental model) adalah konsep diri seseorang yang dengan konsep diri tersebut dia akan mengambil keputusan terbaiknya. Model mental ini akan menghasilkan cara berpikir (mindset). Model mental ini akan membawa seseorang membuat peta konsep atau kerangka kerja dan menyusun rencana untuk mencari solusi dalam setiap masalah yang dihadapinya. Implementasi di sekolah/madrasah sebagai organisasi pembelajar harus mempunyai sistem yang mampu mengembangkan kecakapan individu untuk merenungkan mindset yang dimilikinya.

Visi bersama (shared vision) adalah suatu gambaran umum dari organisasi dan tindakan (kegiatan) organisasi yang mengikat orang-orang secara bersama-sama dari keseluruhan identifikasi dan perasaan yang dituju. Dengan visi misi bersama, organisasi dapat membangun komitmen yang tinggi serta dapat pula menciptakan gambaran-gambaran atau mimpi-mimpi bersama tentang apa yang ingin dicapai, serta prinsip-prinsip dan praktik-praktik penuntun yang akan digunakan dalam memcapai masa depan tersebut..

Belajar tim (team learning) adalah suatu keahlian percakapan dan keahlian berpikir kolektif dalam organisasi. Disini sebagai seorang individu harus mampu berkomunikasi dengan baik dan mampu berpikir bersama dalam organisasinya. Sehingga, sebagai individu dalam organisasi harus memiliki emotional intelligence yang tinggi.

Berpikir sistem (systems thinking) adalah suatu kerangka kerja konseptual, yaitu suatu cara menganalisis dan berpikir tentang suatu kesatuan dari keseluruhan prinsipprinsip organisasi pembelajar. Dengan kemampuan menganalisis dan berpikir tersebut seseorang dapat mengambil tindakan untuk organisasinya.

Berdasarkan uraian diatas maka penulis mengangkat judul penelitian "Kepemimpinan Kepala Sekolah dalam Mengembangkan Organisasi Pembelajar (Learning Organization) di SD Bulukantil Surakarta".

\section{METODE}

Jenis penelitian yang dilakukan dalam penelitian ini adalah penelitian kualitatif. Menurut Sukmadinata (2012), "penelitian kualitatif (qualitative research) adalah suatu penelitian yang ditujukan untuk mendeskripsikan dan menganalisis fenomena, 
peristiwa, aktivitas sosial, sikap, kepercayaan, persepsi, pemikiran orang secara individual maupun kelompok."

Desain penelitian dalam penelitian ini adalah penelitian kualitatif dengan strategi studi kasus. Penelitian studi kasus menurut Darmadi (2013) adalah "studi yang mengeksplorasi suatu masalah dengan batasan terperinci, memiliki pengambilan data yang mendalam, dan menyertakan berbagai sumber informasi."

Data penelitian diperoleh dari wawancara terstruktur dengan kepala sekolah dan beberapa guru.

\section{HASIL DAN PEMBAHASAN}

Peran kepala sekolah dalam mendorong stakeholder untuk mengenali keahlian pribadinya dengan memberikan contoh dengan bersikap karismatik, penuh wibawa, ramah, memiliki sifat seperti jujur, tegas, disiplin, bijaksana dan percaya diri. Misalnya, kepala sekolah SD Negeri Bulukantil mencontohkan sikap penuh wibawa dan ramah kepada guru maupun orang yang ada disekitar dengan memberi salam, berjabat tangan, dan menyapa. Peserta didik juga akan mengikuti apa yang dilakukan kepala sekolah tersebut.

Kepemimpinan seorang kepala sekolah SD Negeri Bulukantil dengan sikap karismatik, penuh wibawa, ramah, jujur, tegas, disiplin, bijaksana dan percaya diri sangat sesuai dengan teori yang disampaikan Nawawi (2009) mengenai kepemimpinan karismatik.

Menurut Toha (2006) mengartikan bahwa: "Kepemimpinan adalah aktivitas untuk mempengaruhi orang-orang supaya diarahkan untuk mencapai tujuan organisasi." Dari pernyataan ini kepala sekolah SD Negeri Bulukantil sudah berhasil memberikan pengaruhnya terhadap seluruh stakeholder yang ada. Dalam menerapkan kedisiplinan, kepala sekolah tidak dengan cara keras untuk menegur stakeholder namun dengan cara memberikan senyuman. Dan terbukti dengan cara itu stakeholder malu dengan sambutan baik kepala sekolah dengan keterlambatannya. Dengan demikian guru akan malu dan tidak mengulanginya lagi.

Peran kepala sekolah dalam menumbuhkan kecakapan memecahkan masalah yang dihadapi stakeholder dengan cara kepala sekolah memberikan bimbingan kepada guru mengenai perencanaan, pelaksanaan dan evaluasi pembelajaran. Lebih lanjut, untuk meningkatkan pengetahuan guru, kepala sekolah juga mendelegasikan dalam seminar, mendelegasikan dalam pelatihan K13, mengadakan KKG tiap bulan yang dilaksanakan satu gugus, untuk kemampuan teknologi pembelajaran, guru diharuskan menguasai computer dengan belajar secara mandiri atau saling meminta bantuan dengan guru lain yang lebih menguasai, dalam meningkatkan pembelajaran dikelas guru disarankan diskusi dengan sesama guru. Seperti yang disampaikan Guclu (1999) Organizations have learning capacity like living organisms. Organizations change their behavior types according to the changing conditions like other living organisms, that is organizations develop their learning capacity.

Bahwa organisasi sekarang diwajibkan untuk menjadi organisasi pembelajaran untuk adaptasi terhadap perubahan cepat di setiap bidang. Jadi, setiap anggota dalam sebuah organisasi harus mampu mengikuti perkembangan organisasinya. Organisasi memiliki cara belajar tersendiri sesuai dengan kebutuhannya, yaitu dengan mengembangkan kapasitas belajar mereka.

Kepala sekolah memiliki peran sebagai pemimpin di sekolahnya dan bertanggung jawab dan memimpin proses pendidikan di sekolahnya, yang berkaitan dengan peningkatan mutu sumber daya manusia, peningkaan profesionalisme guru, karyawan dan semua yang berhubungan dengan sekolah dibawah naungan kepala sekolah. 
Menurut Wahyosumidjo (2010) peran kepala sekolah sebagai pemimpin mencerminkan tanggung jawab kepala sekolah untuk menggerakkan sumber daya yang ada di sekolah. Fungsi kepemimpinan amat penting sebab disamping sebagai penggerak juga berperan sebagai kontrol segala aktifitas guru (dalam rangka peningkatan profesional mengajar), staff, siswa dan sekaligus untuk meneliti persoalan-persoalan yang timbul di lingkungan sekolah.

Untuk menentukan visi misi kepala sekolah SD Negeri Bulukantil melibatkan guru dan pihak- pihak terkait misalnya komite dalam menyusunnya. Dengan disesuaikan dengan kondisi masyarakat dan tuntutan kebutuhan kriteria lulusan (output).

Visi sekolah untuk terwujudnya siswa yang beriman, taqwa, cerdas, trampil unggul dalam prestasi, berwawasan lingkungan dan budaya. Menurut Sunarta (2009) visi adalah masa depan yang realistis, dapat dipercaya, dan menarik bagi organisasi. Visi adalah pernyataan tujuan ke mana suatu organisasi akan dibawa, sebuah masa depan yang lebih baik, lebih diinginkan dibandingkan dengan kondisi sekarang.

Visi yang dijadikan sebagai acuan oleh SD Negeri Bulukantil sendiri disusun secara bersama- sama sehingga dalam pencapaiannya seluruh stakeholder melaksanakan kewajibanya dengan sepenuh hati tanpa adanya suatu paksaan.

Menurut Hamdan (2001) Visi yang baik selalu menjadi inspirasi untuk lahirnya ide-ide baru, temuan-temuan baru, dan hal-hal kreatif lainnya. Visi misi yang baik menghadirkan suasana organisasi yang kondusif untuk hadirnya semangat hidup dan kegairahan berorganisasi. Dari pendapat tersebut sangat sesuai dengan penerapannya di SD Negeri Bulukantil. Visi misi yang disusun secara bersama dan diterapkan bersama pula akan menjadikan seluruh stakeholder di sekolah tersebut memiliki semangat hidup dan kegairahan dalam berorganisasi.

Stakeholder terinspirasi dengan visi misi yang telah disusun bersama dengan menerapkan budaya sekolah diantaranya budaya hidup bersih, budaya disiplin, malu pada diri sendiri, dan budaya sopan santun. Untuk kegiatan-kegiatan yang diterapkan untuk mencapai visi misi di SD Negeri Bulukantil diantaranya pembelajaran secara optimal, penerusan minat dan bakat melalui kegiatan ekstrakulikuler, penanaman pendidikan karakter dalam pembelajaran, dan menjalankan ekstrakulikuler wajib yaitu pramuka.

Menurut Muhaimin dkk., (2009) Belajar tim (team learning) adalah suatu keahlian percakapan dan keahlian berpikir kolektif dalam organisasi. Disini sebagai seorang individu harus mampu berkomunikasi dengan baik dan mampu berpikir bersama dalam organisasinya. Sehingga, sebagai individu dalam organisasi harus memiliki emotional intelligence yang tinggi.

Penerapannya di SD Negeri Bulukantil dengan mengadakan rapat, mengadakan silaturahmi untuk menjaga kedekatan satu dengan yang lain misalnya, berkunjung saat ada yang sakit, berduka, dll. Selain itu kepala sekolah juga mengadakan pendekatan dengan pembicaran fleksibel dalam memecahkan masalah di dalam mencapai visi misi sekolah.

Berdasarkan penjelasan dari seorang guru SD Negeri Bulukantil kepala sekolahnya sangat ramah dan mudah bergaul dengan para guru. Guru juga merasa nyaman untuk mellakukan diskusi mengenai permasalahan yang dihadapinya. Apalagi komunikasi sesama guru di SD Negeri Bulukantil terjalin sangat baik.

Dalam pengambilan suatu kebijakan kepala sekolah SD Negeri Bulukantil melibatkan guru, wali murid, dan komite. Dengan adanya keputusan yang disetujui bersama maka seluruh pihak akan bekerja sama untuk mencapai tujuan tersebut. kondisi seperti ini dalam LO biasanya dikenal dengan berpikir sistem.

Menurut Tanjungsari (2012) Berpikir sistem mencakup pengujian dan refleksi atas seluruh aspek kehidupan organsiasi seperti misi dan strategi, struktur, kultur dan praktik manajerial. Berpikir sistem merupakan bagian dari pemimpin, manajer, dan karyawan yang diharapkan mampu meningkatkan pemahaman dan tindakannya lebih 
fokus pada pengintegrasian bagian atau divisi yang berbeda kearah memaksimalkan kekuatan, meminimalkan kelemahan, serta meningkatkan seluruh operasionalisasi organisasi.

Pelaksanaan LO di SD Negeri Bulukantil memberikan dampak yang baik dengan terlihatnya kebiasaan baik yang ditunjukkan guru, peserta didik, dan kepala sekolah. Adanya beberapa prestasi yang diperoleh guru, kepala sekolah maupun peserta didik. Selain itu lembaga sekolah juga mendapatkan prestasi dengan dinobatkan sebagai lembaga sekolah sehat.

Penerapan learning organization di SD Negeri Bulukantil memberikan dampak yang baik diantaranya dengan predikat guru berprestasi yang dinobatkan kepada beberapa guru di sekolah tersebut, peserta didik mendapatkan juara dari lomba- lomba tingkat kecamatan hingga menjadi perwakilan provinsi, semakin baiknya pembelajaran, adanya kerjasama yang baik antar stakeholder sehingga menjadikan sekolah sebagai organisasi yang kondusif, kepala sekolah SD Negeri Bulukantil mendapatkan predikat Kepala Sekolah berprestasi.

\section{SIMPULAN}

Dari pembahasan sebelumnya mengenai kepemimpinan kepala sekolah dalam mengembangkan organisasi pembelajar (learning organization) di SD Negeri Bulukantil Surakarta dapat disimpulkan bahwa pelaksanaan kepemimpinan kepala sekolah telah memenuhi lima prasyarat sekolah sebagai organisasi pembelajar yang meliputi keahlian pribadi, model mental, visi bersama, pembelajaran tim, dan pemikiran sistem. Dampak yang diperoleh dari penerapan LO dapat dilihat dari prestasi- prestasi yng diperoleh guru, kepala sekolah, peserta didik dan bahkan lembaga sekolah.

\section{DAFTAR PUSTAKA}

Ahmadi, lif Khoiru dan Amri Sofan. 2014. Pengembangan \& Model Pembelajaran Tematik Integratif. Jakarta: PRESTASI PUSTAKA PUBLISHER.

Akdon. 2011. Strategic Management For Educational Management (Manajemen Strategik untuk Manajemen Pendidikan). Bandung: Alfabeta.

Darmadi, Hamid. 2013. Dimensi-Dimensi Metode Penelitian Pendidikan dan Sosial Konsep Dasar dan Implementasi. Pontianak: ALFABETA.

Güçlü, N. 1999. Öğrenen örgütler. Kastamonu Eğitim Dergisi, 7 (2), 117-226.

Hermino, Agustinus. 2014. Manajemen Kurikulum Berbasis Karakter. Bandung. Alfabeta.

Muhaimin, Suti ah, Sugeng Listyo Prabowo. 2009. Manajemen Pendidikan Aplikasinya dalam Penyusunan Rencana Pengembangan Sekolah/Madrasah. Jakarta: Kencana Prenada Media Group.

Hult, G.T.M., Hurley, R.F., Giunipero, L.C., Nichols Jr., E.L..2000. Organizational learning in global supply management: a model and test of internal users and corporate buyers. Decision Sciences 31 (2), 293- 325.

Nawawi, Ismail. 2009. Public Policy, Analisis,Strategi Advokasi Teori dan Praktek. Surabaya: PMN

Ojha, D., Acharya, C., Cooper, D., Transformational leadership and supply chain ambidexterity: Mediating role of supply chain organizational learning and moderating role of uncertainty, International Journal of Production Economics (2018), doi: 10.1016/j.ijpe.2018.01.001.

Senge, P. 2003. Beşinci disiplin. (Çev. İldeniz, A. \& Doğukan, A.) İstanbul: YKY.

Sukmadinata, Nana Syaodih. 2012. Metode Penelitian Pendidikan. Bandung: Remaja Rosdakarya. 
Sunarta. (2009). Peran Visi bagi Pemimpin Organisasi di Tengah Era Globalisasi. INFORMASI, No. 2, XXXV, Th. 2009.

Tanjungsari, Retry Tyas. 2012. Analisis Penerapan Organisasi Pembelajar Pada Rumah Sakit Sentra Medika Depok. Bogor : Institut Pertanian Bogor.

Wahyosumidjo. 2010. Kepemimpinan Kepala Sekolah Tinjauan Teoritik Dan Permasalahannya. Jakarta: PT. Raja Grafindo Persada.

Wahjosumidjo. 2011. Kepemimpinan Kepala Sekolah. Jakarta: PT. Raja Grafindo Persada.. 